\title{
Noninvasive respiratory support outside the intensive care unit for acute respiratory failure related to coronavirus-19 disease: a systematic review and meta-analysis
}

\author{
Gianmaria Cammarota ${ }^{1 *} \mathbb{0}$, Teresa Esposito ${ }^{2}$, Danila Azzolina ${ }^{2}$, Roberto Cosentini ${ }^{3}$, Francesco Menzella ${ }^{4}$, \\ Stefano Aliberti ${ }^{5,6}$, Andrea Coppadoro7, Giacomo Bellani ${ }^{7,8}$, Giuseppe Foti ${ }^{7,8}$, Giacomo Grasselli, ${ }^{6,9}$, \\ Maurizio Cecconi ${ }^{10,11}$, Antonio Pesenti ${ }^{6,9}$, Michele Vitacca ${ }^{12}$, Tom Lawton ${ }^{13}$, V. Marco Ranieri ${ }^{14}$, \\ Sandro Luigi Di Domenico ${ }^{15}$, Onofrio Resta ${ }^{16}$, Antonio Gidaro ${ }^{17}$, Antonella Potalivo ${ }^{18}$, Giuseppe Nardi ${ }^{18}$, \\ Claudia Brusasco ${ }^{19}$, Simonetta Tesoro ${ }^{1}$, Paolo Navalesi ${ }^{20}$, Rosanna Vaschetto ${ }^{2 \dagger}$ and Edoardo De Robertis ${ }^{1 \dagger}$
}

\begin{abstract}
Background: Noninvasive respiratory support (NIRS) has been diffusely employed outside the intensive care unit (ICU) to face the high request of ventilatory support due to the massive influx of patients with acute respiratory failure (ARF) caused by coronavirus-19 disease (COVID-19). We sought to summarize the evidence on clinically relevant outcomes in COVID-19 patients supported by NIV outside the ICU.

Methods: We searched PUBMED ${ }^{\circledR}$, EMBASE$^{\circledR}$, and the Cochrane Controlled Clinical trials register, along with medRxiv and bioRxiv repositories for pre-prints, for observational studies and randomized controlled trials, from inception to the end of February 2021. Two authors independently selected the investigations according to the following criteria: (1) observational study or randomized clinical trials enrolling $\geq 50$ hospitalized patients undergoing NIRS outside the ICU, (2) laboratory-confirmed COVID-19, and (3) at least the intra-hospital mortality reported. Preferred Reporting Items for Systematic reviews and Meta-analysis guidelines were followed. Data extraction was independently performed by two authors to assess: investigation features, demographics and clinical characteristics, treatments employed, NIRS regulations, and clinical outcomes. Methodological index for nonrandomized studies tool was applied to determine the quality of the enrolled studies. The primary outcome was to assess the overall intra-hospital mortality of patients under NIRS outside the ICU. The secondary outcomes included the proportions intra-hospital mortalities of patients who underwent invasive mechanical ventilation following NIRS failure and of those with 'donot-intubate' (DNI) orders.
\end{abstract}

Results: Seventeen investigations (14 peer-reviewed and 3 pre-prints) were included with a low risk of bias and a high heterogeneity, for a total of 3377 patients. The overall intra-hospital mortality of patients receiving NIRS outside

*Correspondence: gmcamma@gmail.com

${ }^{\dagger}$ Rosanna Vaschetto and Edoardo De Robertis share the co-senior authorship

${ }^{1}$ Department of Medicine and Surgery, University of Perugia, Piazza Università 1,06123 Perugia, Italy

Full list of author information is available at the end of the article

(c) The Author(s) 2021. Open Access This article is licensed under a Creative Commons Attribution 4.0 International License, which permits use, sharing, adaptation, distribution and reproduction in any medium or format, as long as you give appropriate credit to the original author(s) and the source, provide a link to the Creative Commons licence, and indicate if changes were made. The images or other third party material in this article are included in the article's Creative Commons licence, unless indicated otherwise in a credit line to the material. If material is not included in the article's Creative Commons licence and your intended use is not permitted by statutory regulation or exceeds the permitted use, you will need to obtain permission directly from the copyright holder. To view a copy of this licence, visit http://creativecommons.org/licenses/by/4.0/. The Creative Commons Public Domain Dedication waiver (http://creativeco mmons.org/publicdomain/zero/1.0/) applies to the data made available in this article, unless otherwise stated in a credit line to the data. 
the ICU was 36\% [30-41\%]. 26\% [21-30\%] of the patients failed NIRS and required intubation, with an intra-hospital mortality rising to $45 \%$ [36-54\%]. 23\% [15-32\%] of the patients received DNI orders with an intra-hospital mortality of 72\% [65-78\%]. Oxygenation on admission was the main source of between-study heterogeneity.

Conclusions: During COVID-19 outbreak, delivering NIRS outside the ICU revealed as a feasible strategy to cope with the massive demand of ventilatory assistance.

Registration: PROSPERO, https://www.crd.york.ac.uk/prospero/, CRD42020224788, December 11, 2020.

Keywords: Noninvasive ventilation, COVID-19, Intra-hospital mortality

\section{Background}

The rapid and massive spread of severe acute respiratory syndrome related to novel coronavirus (SARS-CoV-2) outbreak has put in crisis the healthcare systems of whole nations. Worldwide, the surge capacities of the hospitals have been severely stressed by the massive influx of patients admitted for acute respiratory failure (ARF) caused by coronavirus-19 disease (COVID-19) [1-3]. Among COVID19 patients suffering from hypoxemic ARF, the rate of intubation has been reported ranging from 12 to $33 \%$ [35]. To face this exceptional demand of intensive care unit (ICU) resources, hospitals have increased ICU bays [6] and adapted many general wards into intermediate care units, with the aim of providing respiratory support and clinical monitoring to those hypoxemic ARF patients in whom the sole conventional oxygen supplement is ineffective [7].

Moreover, at the very beginning of the pandemic, the rate of patients receiving noninvasive respiratory support (NIRS) upon ICU admission was reported to range from 11 [8] (in Italy) to 56\% (in China) [9]. At the same time, several studies demonstrated that NIRS outside the ICU was feasible and effective in preventing invasive mechanical ventilation (IMV) $[10,11]$. However, a major concern while treating hypoxemic ARF patients by NIRS is related to the failure rate of NIRS, which could occur even in $50 \%$ of the cases with consequent recourse to IMV [12]. Also, excessive prolongation of NIRS may worsen lung injury because of patient self-inflicted lung injury occurrence [13] or delay IMV $[14,15]$.

The aim of this systematic review and meta-analysis was to estimate the overall intra-hospital mortality of COVID-19 patients assisted through NIRS outside the ICU and quantify the proportion of patients who failed NIRS and were subsequently intubated and treated in the ICU. Also, the estimate of patients who received NIRS as a ceiling ventilatory therapy and the related intra-hospital mortality were investigated.

\section{Methods}

Our systematic review and meta-analysis was realized following the Preferred Reporting Items for Systematic reviews and Meta-analysis (PRISMA) guidelines [16] and was registered on PROSPERO (CRD42020224788).

\section{PICO question}

We sought information about the application of NIRSi.e., continuous positive airway pressure (CPAP) or noninvasive bi-level ventilation-outside the ICU (I) in adult patients admitted for hypoxemic ARF COVID-19 related $(\mathrm{P})$ with or without comparator $(\mathrm{C})$ and aimed to ascertain the intra-hospital mortality $(\mathrm{O})$. For overall intra-hospital mortality we intended the punctual intrahospital mortality reported by each enrolled study at database closure.

\section{Search methods and study selection}

We searched PUBMED ${ }^{\circledR}, \mathrm{EMBASE}^{\circledR}$, and the Cochrane Controlled Clinical trials register from inception to February 2021 for observational studies and randomized controlled trials without language restrictions. The search was performed using the following terms, combined according to database syntax (see Additional file 1 for search strategy): 'COVID-19,' 'novel coronavirus 2019, 'SARS-CoV-2,' 'severe acute respiratory syndrome coronavirus related,' 'SARS-CoV-19,' 'positive pressure respiration,' 'NIV,' 'noninvasive ventilation,' 'CPAP,' 'continuous positive airway pressure,' 'noninvasive positive pressure respiration,' 'NIPPV', 'NRS', and 'noninvasive respiratory support.' For NIRS outside the ICU, we meant all the modalities of noninvasive bi-level and CPAP, regardless of the interface used, adopted to assist COVID-19 patients with hypoxemic ARF, with the exceptions of the high-flow nasal cannula.

We also reviewed the references of selected papers, review articles, commentaries, and editorials on this topic to identify other studies of interest missed during the primary search. Moreover, we surveyed medRxiv and bioRxiv, free online repositories for preprints in health science, from inception to end of February 2021, searching for clinical and preclinical investigations about NIRS application in COVID-19 patients outside the ICU.

Two authors (GC and TE) independently evaluated titles and abstracts obtained from the search to select investigations responding to the following inclusion requests: (1) observational study or randomized clinical trials enrolling $\geq 50$ symptomatic hospitalized patients undergoing NIRS outside the ICU, (2) 
laboratory-confirmed COVID-19 defined by a positive result on a reverse-transcriptase-polymerase chain reaction assay of a nasopharyngeal and oropharyngeal swab or a sputum specimen, and (3) at least the primary outcome reported by the study. Case reports and case series with less than 50 patients were excluded, as they may observe no events due to the small size [17]. When multiple publications of the same research group/center described potentially overlapping cohorts, the authors selected the most recent publications. The same authors independently screened the full texts, and any disagreement was resolved through discussion or involving a third review author (EDR). When necessary, the corresponding authors of the included studies were contacted to obtain missing data related to study demographics, methods, outcomes, and clinical characteristics of patients analyzed.

\section{Data extraction and study quality}

Data extraction was independently performed by two authors (GC and TE) who screened and selected the included studies extracted. Any disagreement was resolved by discussion or involving a third review author (EDR). Extracted data included: investigation features (e.g., study design, setting), demographic characteristics (e.g., age, sex, body mass index), presence of comorbidities (with special attention to hypertension, diabetes, kidney disease, respiratory disease, and cardiac disease), characteristics at hospital admission (e.g., oxygenation, respiratory rate, laboratory tests), treatments, NIRS regulations, and clinical outcomes.

The methodological quality of selected articles was assessed by an index that classifies nonrandomized studies as adequate, inadequate, or unclear [18].

\section{Statistical analysis}

The analysis was carried out on the data extracted from peer-reviewed manuscripts in combination with data obtained from pre-print investigations.

The descriptive analysis was conducted for all the selected variables considered in the included studies. Continuous or noncontinuous variables were reported as appropriate. Proportions with $95 \%$ confidence intervals $(\mathrm{CI})$ and model fitting weights were computed using the DerSimonian-Laird method with a random-effects model, based on the expected heterogeneity. Heterogeneity across the studies was assessed through $\mathrm{Q}$ and $\mathrm{I}^{2}$ tests both, which were considered significant when the $p$-value

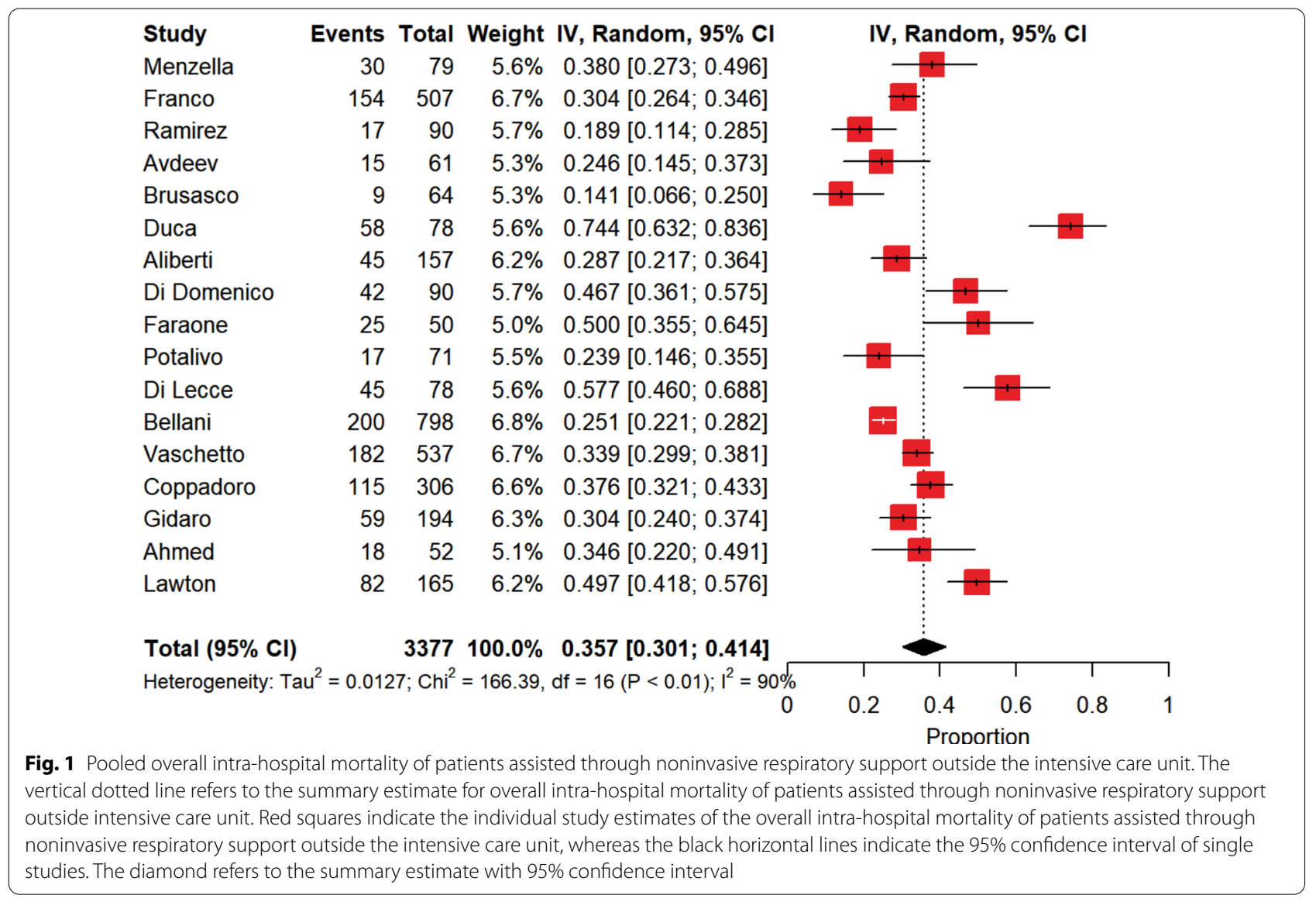




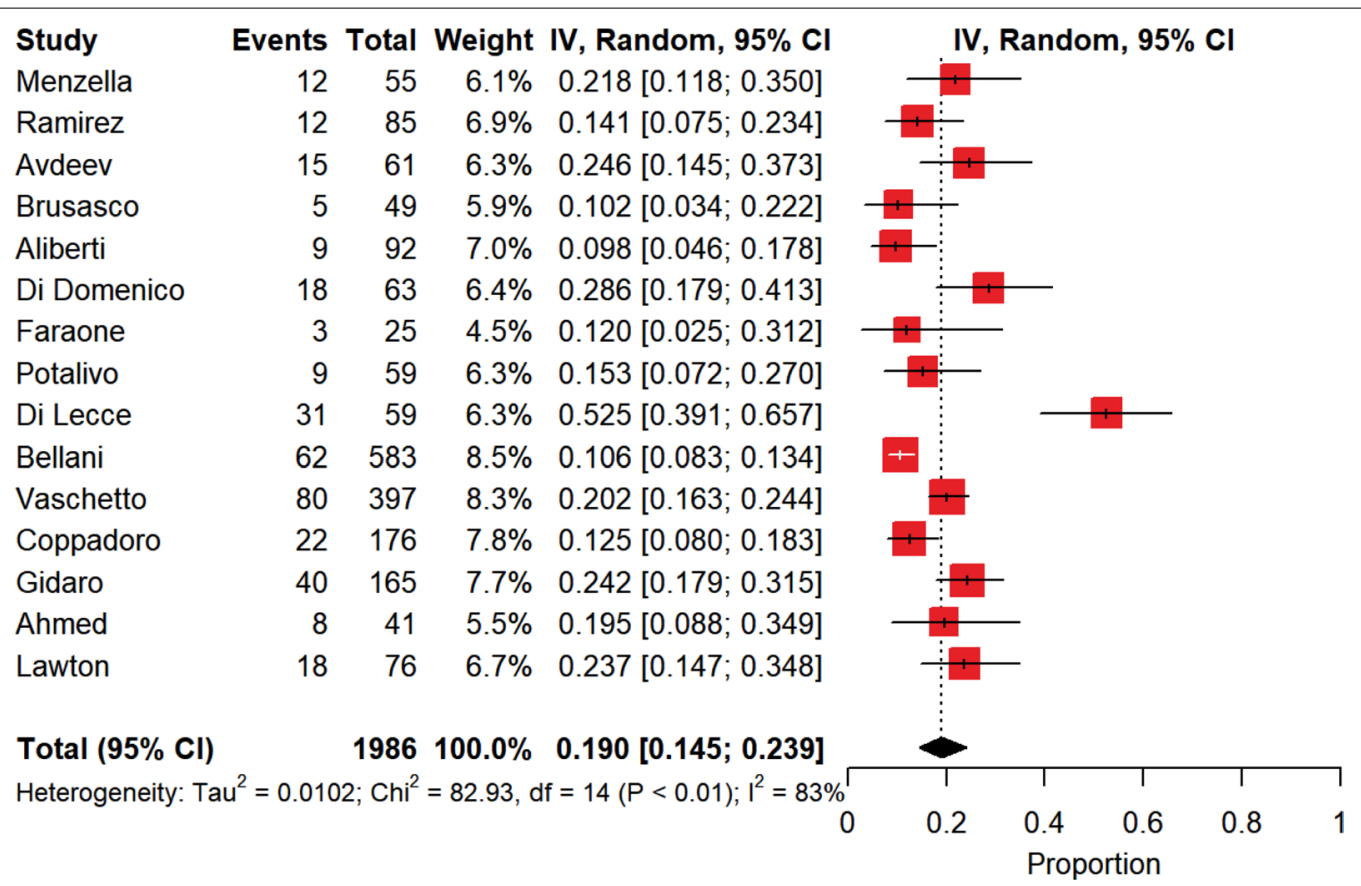

Fig. 2 Pooled intra-hospital mortality of patients assisted through noninvasive respiratory support outside the intensive care unit, net of the patients subjected to limitations of care. The vertical dotted line refers to the summary estimate for intra-hospital mortality of patients assisted through noninvasive respiratory support outside intensive care unit, excluding the patients subjected to limitations of care. Red squares indicate the individual study estimates of the overall intra-hospital mortality of patients assisted through noninvasive respiratory support outside the intensive care unit, excluding the patients subjected to limitations of care, whereas the black horizontal lines indicate the $95 \%$ confidence interval of single studies. The diamond refers to the summary estimate with $95 \%$ confidence interval

was $<0.05$ and $I^{2}>75 \%$ [19], and graphical evaluation of forest plots.

A general linear (mixed-effects) meta-regression model was performed by using the outcome as the dependent variable and the study size as the independent variable. Meta-regression was conducted to assess, in patients admitted for COVID-19 undergoing NIRS, the impact of age, gender, arterial oxygen tension to inspired oxygen fraction ratio $\left(\mathrm{PaO}_{2} / \mathrm{FiO}_{2}\right)$ acquired on hospital admission, number of intubations, and number of do-notintubate' (DNI) orders patients on the clinical outcomes investigated. Again, the observations were weighted by the inverse variance of the estimate to allow for possible heteroscedasticity.

Statistical analyses were conducted using R3.5.2 software (The $\mathrm{R}$ foundation).

\section{Results}

As depicted in Additional file 2, a total of 1956 records were identified from the search, including 1045 peerreviewed studies and 911 pre-prints studies. After duplicates exclusion and full-text evaluation, 17 eligible studies were identified (14 peer-reviewed and 3 preprints) for a total of 18,204 patients with a suspected

(See figure on next page.)

Fig. 3 Summary estimates of intubated patients following noninvasive respiratory support failure and of those patients who continued noninvasive respiratory support and did not experience intubation. a Summary estimate of intubated patients following noninvasive respiratory support failure. The vertical dotted line refers to the summary estimate of intubation in patients who failed noninvasive respiratory support. Red squares indicate the individual study estimates of the intubated patients following noninvasive respiratory support failure, whereas the black horizontal lines indicate the $95 \%$ confidence interval of single studies. The diamond refers to the summary estimate with $95 \%$ confidence interval. b Summary estimate of patients with noninvasive respiratory support who did not experience intubation. The vertical dotted line refers to the summary estimate of patients who continued noninvasive respiratory support and were not intubated. Red squares indicate the individual study estimates of patients who continued noninvasive respiratory support and were not intubated, whereas the black horizontal lines indicate the $95 \%$ confidence interval of single studies. The diamond refers to the summary estimate with $95 \%$ confidence interval 
a
Study

Ahmed

Aliberti

Avdeev

Bellani

Brusasco

Coppadoro

Di Domenico

Di Lecce

Duca

Faraone

Franco

Gidaro

Lawton

Menzella

Potalivo

Ramirez

Vaschetto
Events Total Weight IV, Random, $95 \% \mathrm{CI}$

$\begin{array}{llll}21 & 52 & 4.8 \% & 0.404\end{array}$ [0.270:0.549]

$34 \quad 157 \quad 6.3 \% \quad 0.217[0.155 ; 0.289]$

$132798 \quad 7.2 \% \quad 0.165[0.140 ; 0.193]$

$7 \quad 64 \quad 5.1 \% \quad 0.109[0.045 ; 0.212]$

$54 \quad 306 \quad 6.8 \% \quad 0.176[0.135 ; 0.224]$

$36 \quad 90 \quad 5.6 \% \quad 0.400[0.298 ; 0.509]$

$29 \quad 78 \quad 5.4 \% \quad 0.372[0.265 ; 0.489]$

$26 \quad 78 \quad 5.4 \% \quad 0.333[0.231 ; 0.449]$

$9 \quad 50 \quad 4.7 \% \quad 0.180[0.086 ; 0.314]$

$131 \quad 507 \quad 7.1 \% \quad 0.258[0.221 ; 0.299]$

$40 \quad 194 \quad 6.5 \% \quad 0.206[0.152 ; 0.270]$

$23 \quad 165 \quad 6.4 \% \quad 0.139[0.090 ; 0.202]$

$21 \quad 79 \quad 5.5 \% \quad 0.266[0.173 ; 0.377]$

$25 \quad 71 \quad 5.3 \% \quad 0.352[0.242 ; 0.475]$

$29 \quad 90 \quad 5.6 \% \quad 0.322[0.228 ; 0.429]$

$180 \quad 537 \quad 7.1 \% \quad 0.335[0.295 ; 0.377]$ $\begin{array}{llll}17 & 61 & 5.1 \% & 0.279\end{array}[0.171 ; 0.408]$

Total $(95 \% \mathrm{Cl})$

$3377100.0 \% \quad 0.256[0.214 ; 0.301]$

Heterogeneity: $\mathrm{Tau}^{2}=0.0084 ; \mathrm{Chi}^{2}=116.06, \mathrm{df}=16(\mathrm{P}<0.01) ; \mathrm{I}^{2}=86 \%$

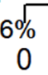

b
Study

Ahmed

Aliberti

Bellani

Brusasco

Coppadoro

Di Domenico

Di Lecce

Duca

Faraone

Franco

Gidaro

Lawton

Menzella

Potalivo

Ramirez

Vaschetto
Avdeev
Events Total Weight IV, Random, 95\% Cl

$\begin{array}{llll}31 & 52 & 4.8 \% & 0.596\end{array}[0.451 ; 0.730]$

$\begin{array}{llll}123 & 157 & 6.3 \% & 0.783 \\ {[} & 0.711 ; 0.845]\end{array}$

$44 \quad 61 \quad 5.1 \% \quad 0.721[0.592 ; 0.829]$

$\begin{array}{llll}666 & 798 & 7.2 \% & 0.835\end{array}[0.807 ; 0.860]$

$57 \quad 64 \quad 5.1 \% \quad 0.891[0.788 ; 0.955]$

$252 \quad 306 \quad 6.8 \% \quad 0.824[0.776 ; 0.865]$

$\begin{array}{llll}54 & 90 & 5.6 \% & 0.600\end{array}[0.491 ; 0.702]$

$49 \quad 78 \quad 5.4 \% \quad 0.628[0.511 ; 0.735]$

$\begin{array}{llll}52 & 78 & 5.4 \% & 0.667\end{array}[0.551 ; 0.769]$

$41 \quad 50 \quad 4.7 \% \quad 0.820[0.686 ; 0.914]$

$\left.\begin{array}{llll}376 & 507 & 7.1 \% & 0.742[0.701 ; 0.779\end{array}\right]$

$154 \quad 194 \quad 6.5 \% \quad 0.794[0.730 ; 0.848]$

$142 \quad 165 \quad 6.4 \% \quad 0.861[0.798 ; 0.910]$

$\begin{array}{llll}58 & 79 & 5.5 \% & 0.734\end{array}[0.623 ; 0.827]$

$46 \quad 71 \quad 5.3 \% \quad 0.648[0.525 ; 0.758]$

$61 \quad 90 \quad 5.6 \% \quad 0.678[0.571 ; 0.772]$

$357 \quad 537 \quad 7.1 \% \quad 0.665[0.623 ; 0.705]$

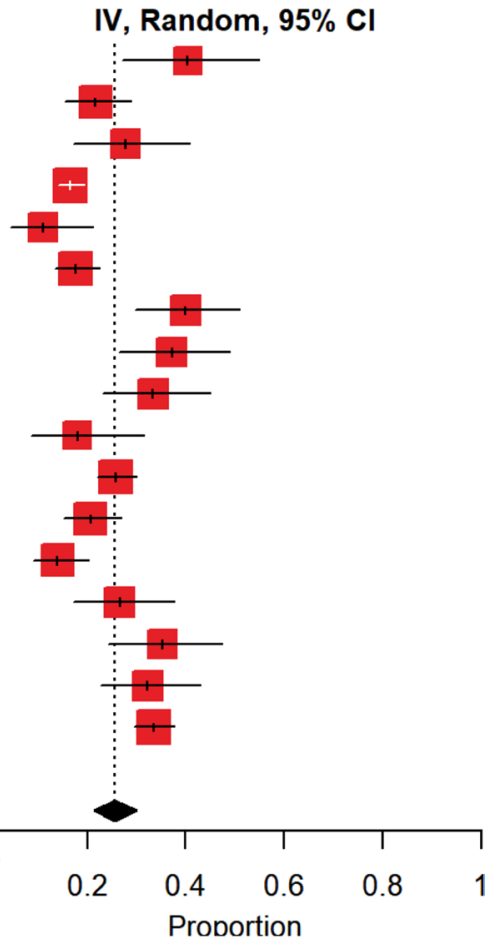

Total $(95 \% \mathrm{Cl}) \quad 3377 \quad 100.0 \% \quad 0.744[0.699 ; 0.786]$

Heterogeneity: $\mathrm{Tau}^{2}=0.0084 ; \mathrm{Chi}^{2}=116.06, \mathrm{df}=16(\mathrm{P}<0.01) ; \mathrm{I}^{2}=86 \%$

Fig. 3 (See legend on previous page.)

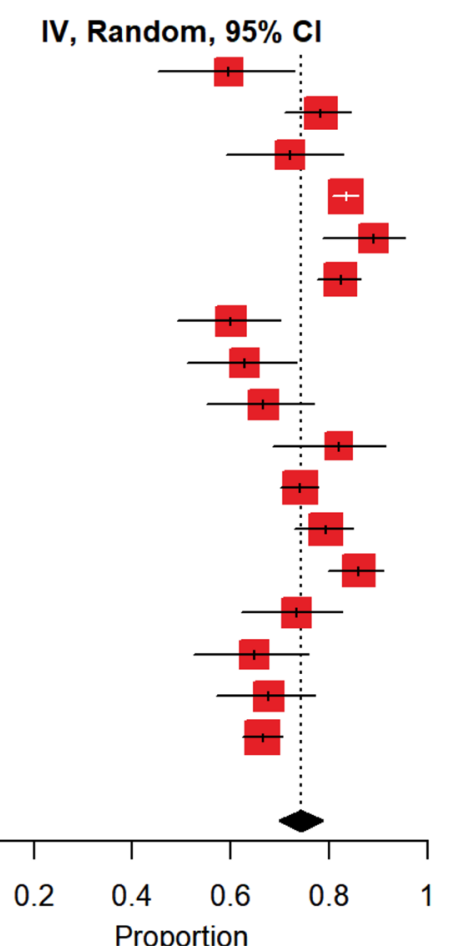

Pronortion 
COVID-19-related infection at hospital admission of whom 3377 received NIRS outside ICU [10, 11, 20-34].

\section{Characteristics of the included studies}

The main characteristics of the included studies are reported in Additional file 3-Table 1. Except for one study conducted in Russia and two investigations performed in the UK, the leading part of the studies was conducted in Italy (82.4\%) during the first wave of COVID-19 pandemic, from the end of February to the end of May 2020. Among the 17 enrolled investigations, 11 (64.7\%) were single-center studies, whereas $6(35.3 \%)$ were multicenter studies: of these, 2 investigations (33.3\%) were prospectively conducted, while 4 were retrospectively carried out. The overall risk of bias was low for the studies included. The methodological quality of the included investigations assessed through methodological index for nonrandomized studies (MINORS) tool is reported in Additional file 3-Table 2 and Additional file 4.

\section{Patient characteristics}

The demographic characteristics are described in Additional file 3-Table 3. A total of 3377 patients were under NIRS outside the ICU. Of these, 2696 (79.8\%) were males with an average age ranging from 60 to 75 years and an average body mass index ranging from 27 to $31.9 \mathrm{~kg} /$ $\mathrm{cm}^{2}$ (2413/3377 patients). The mean Charlson comorbidity index varied from a minimum of 1 to a maximum of 4 (1037/3377 patients). Among comorbidities, hypertension was reported in a higher number of studies compared to other comorbidities. Patients' clinical characteristics on hospital admission are presented in Additional file 3-Table 4. $\mathrm{PaO}_{2} / \mathrm{FiO}_{2}$ at hospital admission was the most reported clinical variable in the included studies. Additional file 3-Table 5 describes the pharmacological therapies administered and the application of awake-prone position. The rate of hydroxychloroquine administration was the most reported pharmacological therapy among the included investigations. Eight studies reported the application of awake-prone position during NIRS. NIRS settings are described in Additional file 3Table 6. When reported, CPAP was applied in 2764/3047 of the patients and helmet interface was used in $1855 / 2690$ of the cases. Positive end-expiratory pressure varied from a mean value of 7 to $15 \mathrm{~cm} \mathrm{H}_{2} \mathrm{O}(2870 / 3377$ patients) and $\mathrm{FiO}_{2}$ ranged from a mean value of 50 to $68 \%$ (2467/3377 patients), respectively.

\section{Clinical outcomes}

Figure 1 depicts the overall intra-hospital mortality in patients noninvasively ventilated outside the ICU. Overall intra-hospital mortality rate was 36\% [30-41\%] in COVID-19 patients who received NIRS outside the ICU, with a high between-study heterogeneity $(p<0.0001$, $\left.I^{2}=90.4 \%\right)$.

As depicted in Fig. 2, when patients subjected to DNI orders were excluded from the global population of patients assisted by NIRS outside the ICU, the pooled intra-hospital mortality was $19 \%[15-24 \%]$ with a high between-study heterogeneity $\left(p<0.01, I^{2}=83 \%\right)$.

The estimate of intubation rate is shown in Fig. 3a. Pooled intubation estimate was 26\% [21-30\%], with a high between-study heterogeneity $(p<0.0001$, $\left.I^{2}=86.2 \%\right)$. In this case, the source of heterogeneity was only ascribed to $\mathrm{PaO}_{2} / \mathrm{FiO}_{2}$ on admission $(p<0.0001$, $\left.I^{2}=73.4 \%\right)$. The causes of IMV onset and the intubation criteria are described in Additional file 3-Tables 7 and 8. Among the included studies, 8 investigations attributed refractory hypoxemia to the cause of intubation.

The summary estimate of nonintubated patients is depicted in Fig. 3b. Patients were not intubated in $74 \%$ [70-79\%] of the cases, with a high between-study heterogeneity $\left(p<0.0001, I^{2}=86.2 \%\right)$. Also in this case, this heterogeneity was only due to $\mathrm{PaO}_{2} / \mathrm{FiO}_{2}$ on admission $\left(p<0.0001, I^{2}=73.4 \%\right)$. Among patients who did not experience intubation, a DNI order was expressed in a summary estimate of 23\% [15-32\%] of the cases (Fig. 4a), whereas patients were deemed as deserving 'full treatment' in 45\% [37-54\%] of the cases (Fig. 4b), with a high heterogeneity for both (DNI, $p<0.0001, I^{2}=96.8 \%$; 'full treatment', $\left.p<0.0001, I^{2}=95.0 \%\right)$. As depicted in Fig. $5 \mathrm{a}$, in patients who failed NIV and were subsequently intubated, intra-hospital mortality reached 45\% [36-54\%], while in those subjects under NIRS who did not experience IMV intra-hospital mortality was of 30\% [23-37\%] (Fig. 5b), with high between-study heterogeneities in both the cases (intubation, $p<0.0001, I^{2}=82.0 \%$; nonintubation, $\left.p<0.0001, I^{2}=92.0 \%\right)$. In the subset of NIRS

\section{(See figure on next page.)}

Fig. 4 Summary estimates of patients with limitations of care and of those under 'full treatment' who were not intubated. a Summary estimate of nonintubated patients with limitations of care. The vertical dotted line refers to the summary estimate of patients with limitations of care. Red squares indicate the individual study estimates of the patients with limitations of care, whereas the black horizontal lines indicate the $95 \%$ confidence interval of single studies. The diamond refers to the summary estimate with $95 \%$ confidence interval. b Summary estimate of patients under 'full treatment' who were not intubated. The vertical dotted line refers to the summary estimate of patients under 'full treatment' who were not intubated. Red squares indicate the individual study estimates of patients under 'full treatment' who were not intubated, whereas the black horizontal lines indicate the $95 \%$ confidence interval of single studies. The diamond refers to the summary estimate with $95 \%$ confidence interval 
a

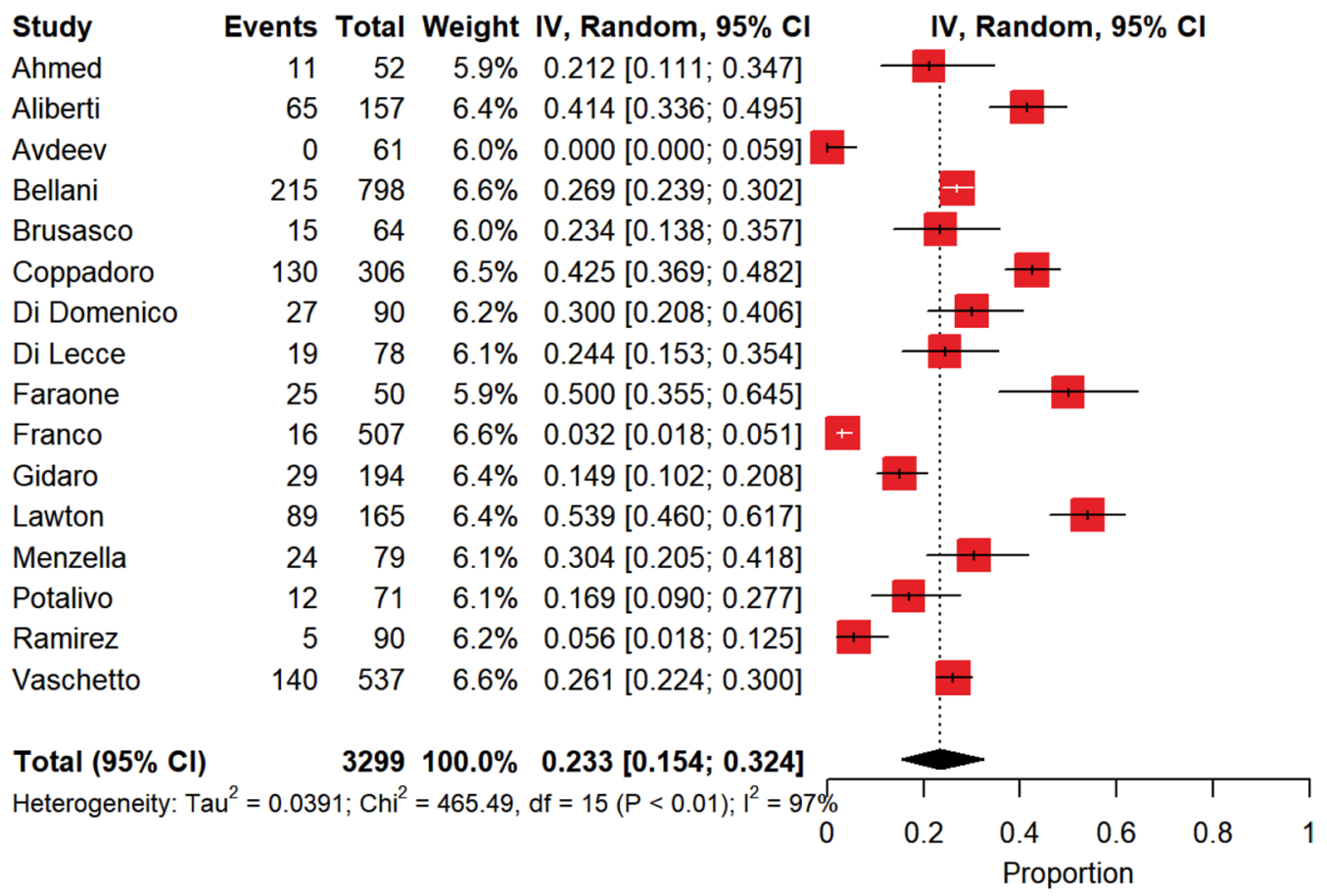

b

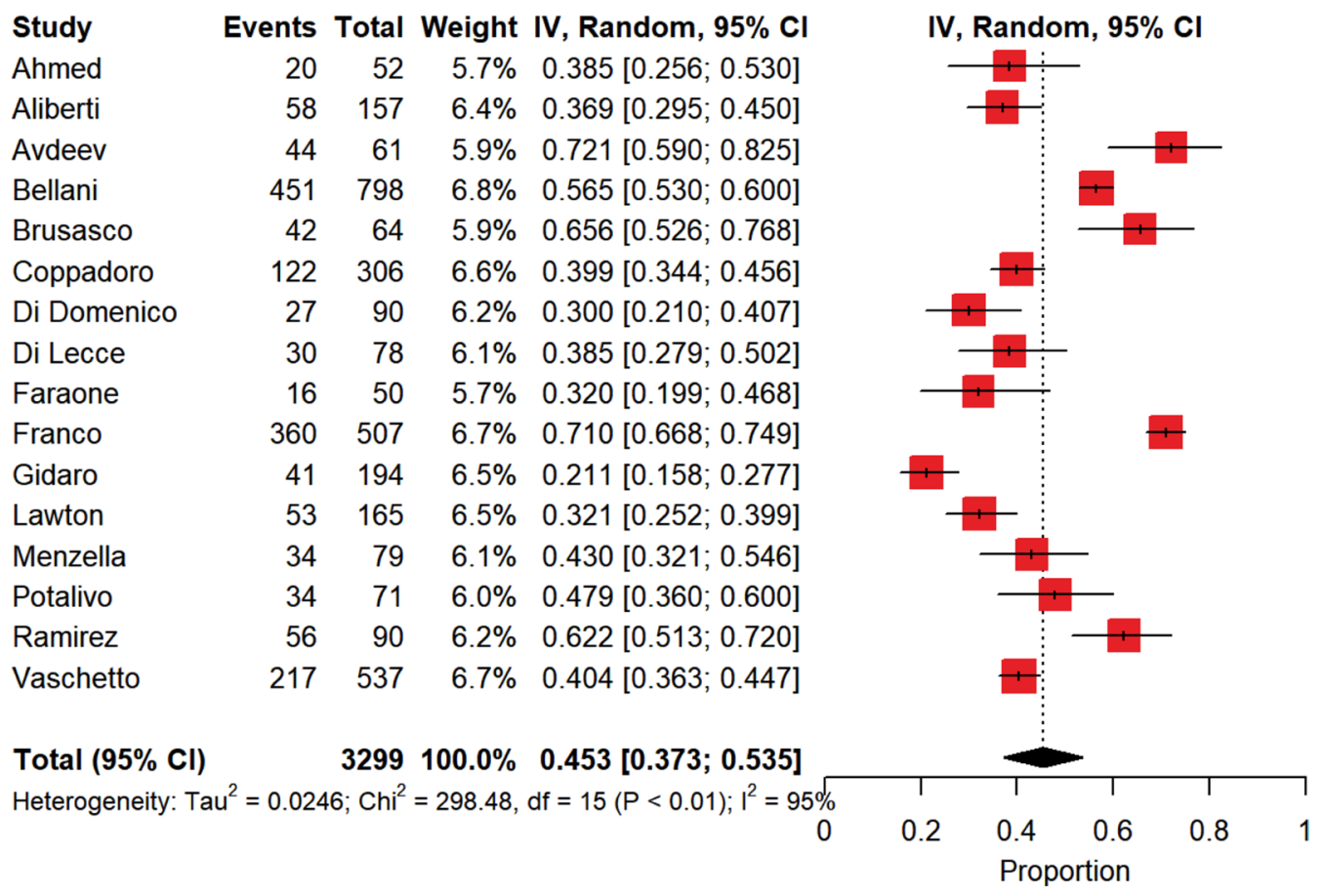

Fig. 4 (See legend on previous page.) 
patients with DNI orders (Fig. 6a), intra-hospital mortality was of $72 \%$ [65-78\%], with a moderate between-study heterogeneity $\left(p<0.0004, I^{2}=65.0 \%\right)$, while in those under NIRS deserving 'full treatment' (Fig. 6b) intrahospital mortality reached $2.6 \%$ [0.3-6.3\%], with a high between-study heterogeneity $\left(p<0.0001, I^{2}=85.7 \%\right)$.

In Additional file 3-Table 9, hospital length of stay, NIRS and IMV duration, along with time lag between NIRS and IMV onset were reported. Interestingly, NIRSto-IMV time lag varied from a mean value of $72 \mathrm{~h}$ to a mean value of $137 \mathrm{~h}$ (1524/3377 patients).

\section{Discussion}

In the present systematic review and meta-analysis patients admitted for COVID-19 and requiring NIRS outside the ICU were characterized by an overall intrahospital mortality of $36 \%$.

During COVID-19 outbreak, NIRS was demonstrated to be feasible both in- and outside ICU, in a percentage of patients ranging between 11 and $62 \%$ [3, 8, 9, 35, 36]. Despite the lack of a strong recommendation in pandemic viral illness [15], several observational studies suggest that the application of NIRS was clinically useful in stabilizing the clinical course of patients with mildto-moderate ARF COVID-19 related [3, 9]. However, due to a potential imbalance between the exceptional demand for ventilatory assistance during COVID-19 pandemic and hospital surge capacity, one might suppose that NIRS practiced outside ICU would be characterized by an increase in intra-hospital mortality compared to NIRS applied in the ICU for COVID-19 patients with ARF. Indeed, data from our 3377 patients showed that (1) NIRS outside the ICU was feasible in the COVID-19 pandemic scenario and (2) in our global patients' population receiving NIRS outside the ICU, the pooled intra-hospital mortality of $19 \%$, net of patients subjected to DNI orders, was quite similar to intra-hospital mortality observed in the helmet NIRS group from a recent randomized-controlled trial, conducted in COVID-19 patients admitted to ICU [38].
In our population pooled intubation rate was of $26 \%$. This finding kept with IMV onset reported in severe acute respiratory syndrome [39], but was lower than that described for H1N1 pneumonia [40], and middle eastern respiratory syndrome outbreak [41]. In our context, the most reported cause of intubation was refractory hypoxemia, when the reasons for IMV commencement were described, with an average NIRS-to-IMV time lag varying from a minimum of $55 \mathrm{~h}$ to a maximum of $137 \mathrm{~h}$, respectively, when reported. Once intubated, in this subset of patients who experienced NIRS failure, we observed a pooled intra-hospital mortality of $45 \%$, consistent with that observed in intubated ARDS patients who failed NIRS [37]. In interpreting our data, it is worth to consider that an undue prolongation of NIRS with a consequent delayed intubation probably played a key role in the lung injury progression, as described by patient self-induced lung injury theory [42].

The rate of DNI order application has increased over time in the last two decades, reaching $32 \%$ in patients admitted for ARF undergoing NIRS or high flow oxygen therapy [43], in nonpandemic context. In this subset of patients, a pooled survival of $56 \%$ at hospital discharge has been reported regardless of whether patients were managed in the ICU or hospital ward [44]. However, the DNI order decision-making process is particularly tricky because it is affected by demographic and clinical factors, i.e., age and illness severity, along with patient/ family involvement [43]. According to our findings, in the COVID-19 pandemic context, the summary estimate of the patients, in whom a DNI decision was pursued, was $23 \%$ with a pooled intra-hospital mortality of $72 \%$. It is worth to point out that our data were obtained during the first wave of COVID-19 outbreak, with the welldescribed concerns of hospital and ICU surge capacity [7, 45].

Among the variables investigated, $\mathrm{PaO}_{2} / \mathrm{FiO}_{2}$ on admission was the main factor sustaining the between-study heterogeneities of the investigated outcomes. These data suggest that, in our context, there was most likely a great variability

\footnotetext{
(See figure on next page.)

Fig. 5 Summary estimates of intra-hospital mortality observed in intubated patients following noninvasive respiratory support failure and of that reported in patients who continued noninvasive respiratory support and did not experience intubation. a Summary estimate of intra-hospital mortality observed in intubated patients following noninvasive respiratory support failure. The vertical dotted line refers to the summary estimate of intra-hospital mortality observed in intubated patients who failed noninvasive respiratory support. Red squares indicate the individual study estimates of intra-hospital mortality observed in intubated patients following noninvasive respiratory support failure, whereas the black horizontal lines indicate the $95 \%$ confidence interval of single studies. The diamond refers to the summary estimate with $95 \%$ confidence interval. b Summary estimate of intra-hospital mortality of patients with noninvasive respiratory support who did not experience intubation. The vertical dotted line refers to the summary estimate of intra-hospital mortality of patients with noninvasive ventilation who did not experience intubation. Red squares indicate the individual study estimates of intra-hospital mortality of patients with noninvasive respiratory support who did not experience intubation, whereas the black horizontal lines indicate the $95 \%$ confidence interval of single studies. The diamond refers to the summary estimate with $95 \%$ confidence interval
} 
a

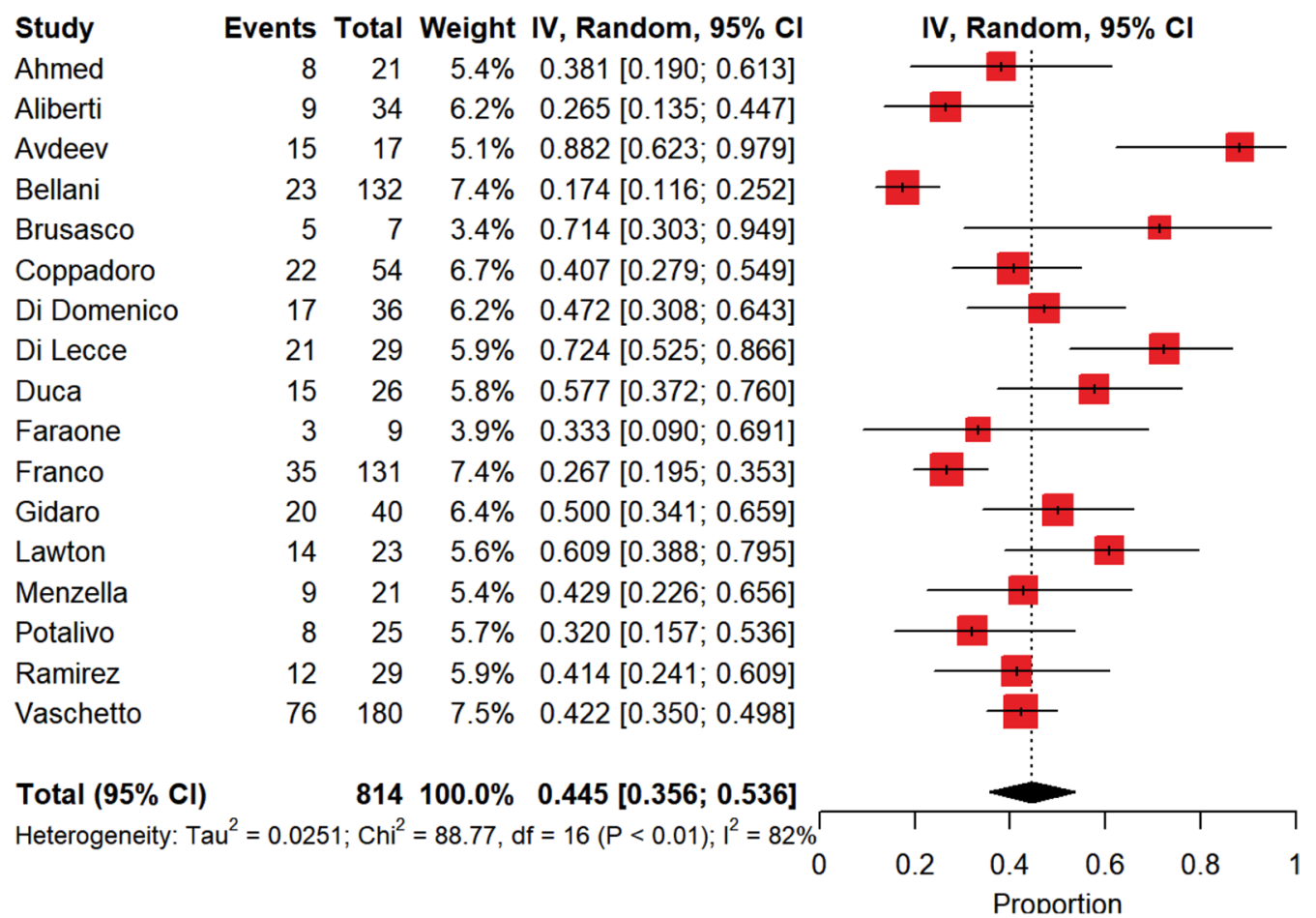

b

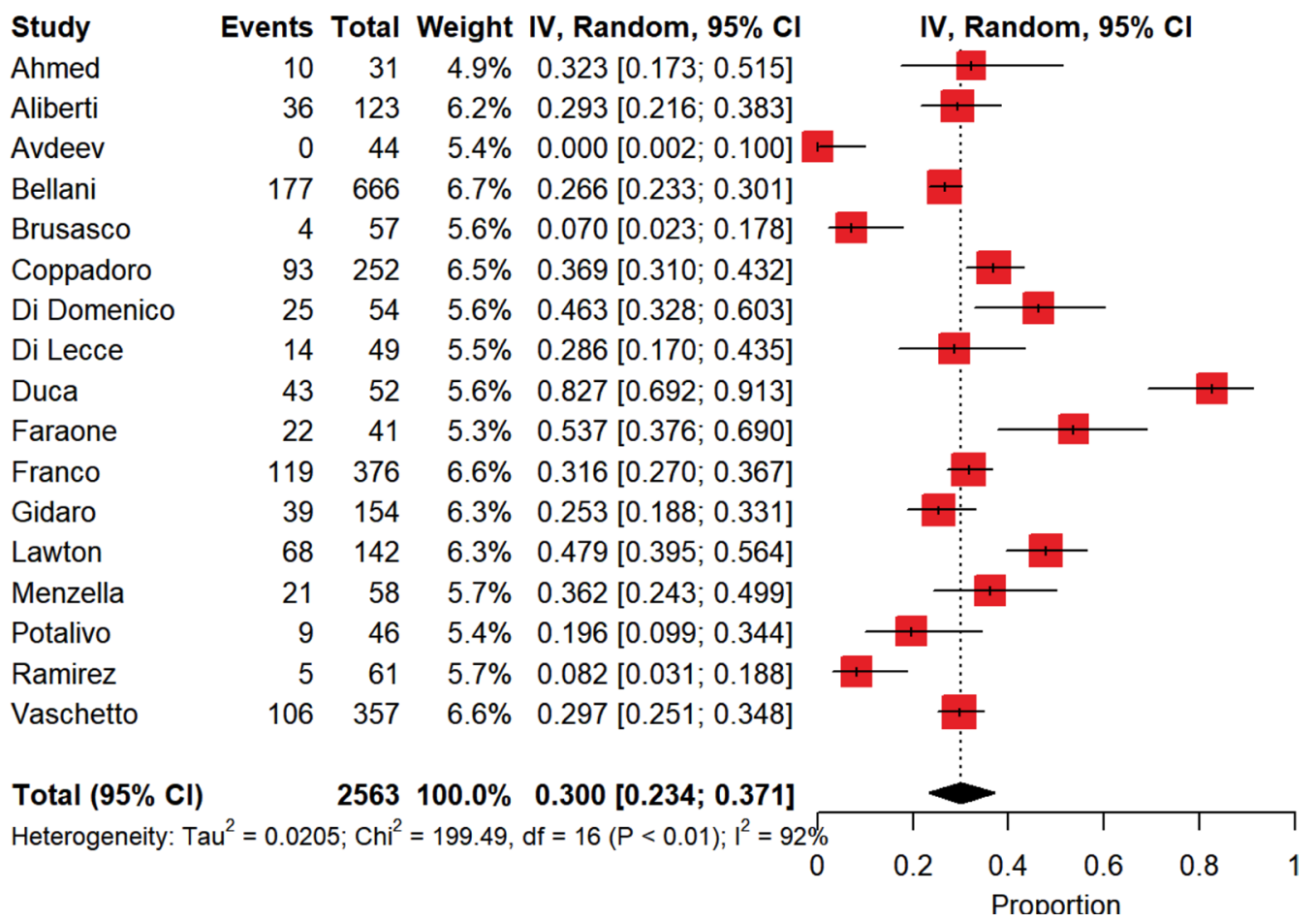

Fig. 5 (See legend on previous page.) 
a

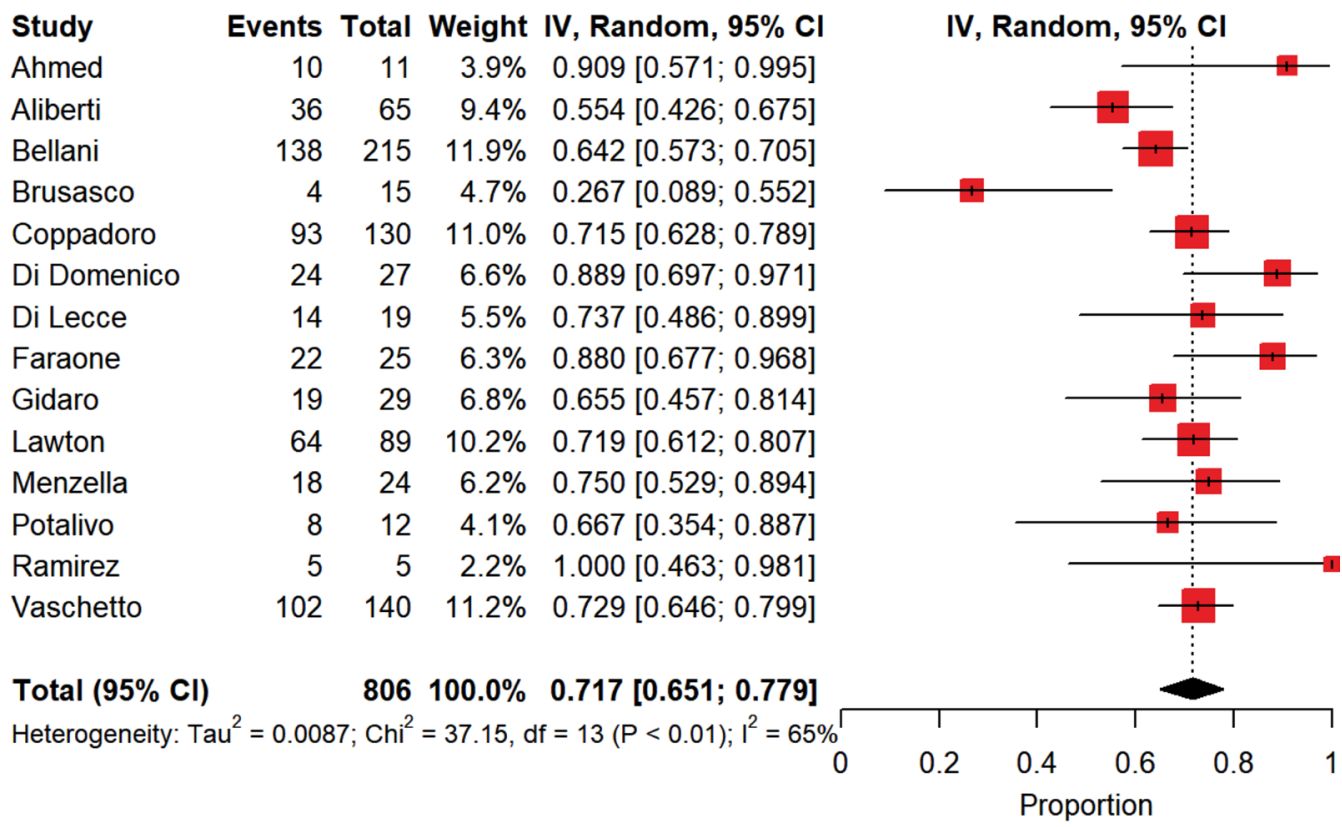

b

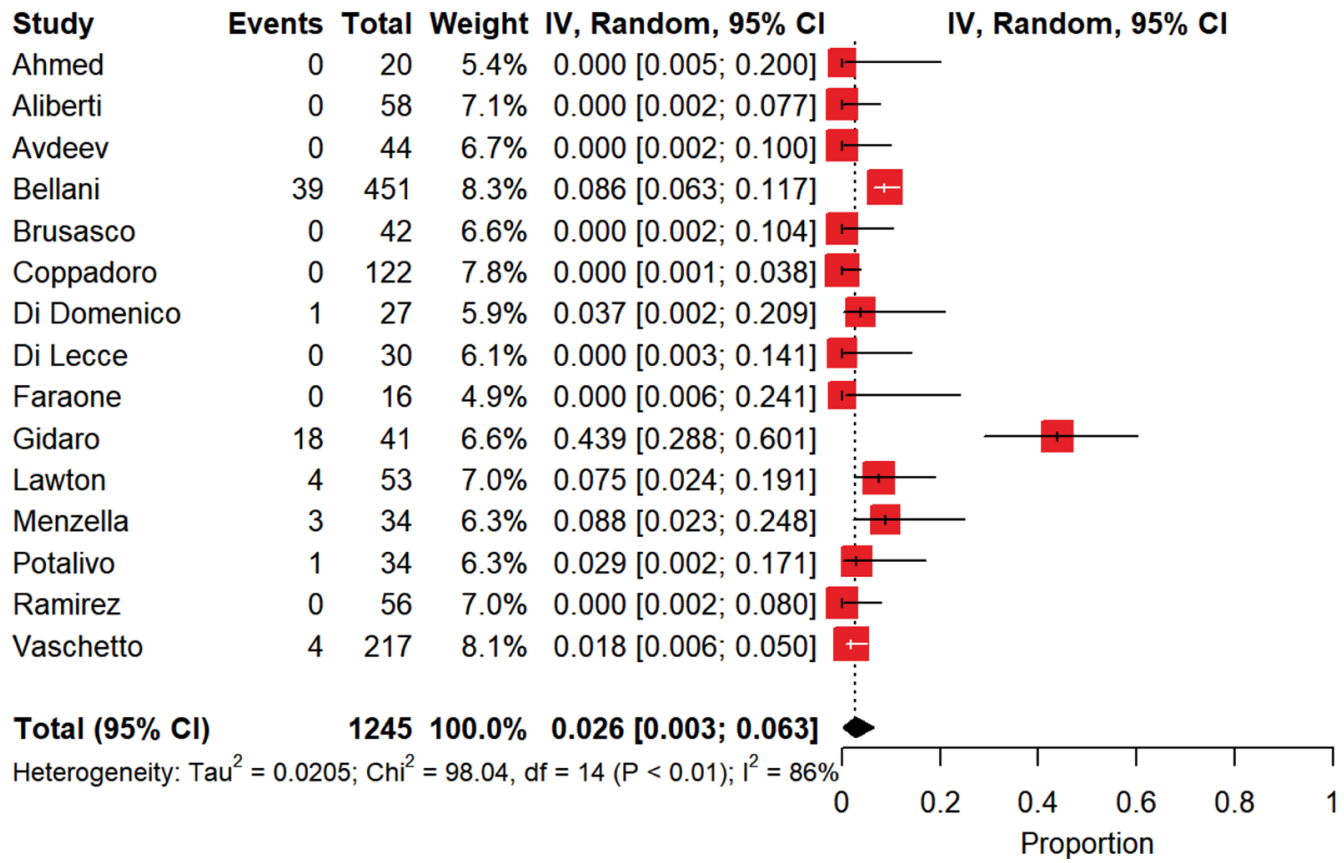

Fig. 6 Summary estimates of intra-hospital mortality observed in patients with limitations of care and of that reported in patients under 'full treatment' who were not intubated. a Summary estimate of intra-hospital mortality observed in patients with limitations of care. The vertical dotted line refers to the summary estimate of intra-hospital mortality observed in patients with limitations of care. Red squares indicate the individual study estimates of intra-hospital mortality observed in patients with limitations of care, whereas the black horizontal lines indicate the $95 \%$ confidence interval of single studies. The diamond refers to the summary estimate with $95 \%$ confidence interval. b Summary estimate of intra-hospital mortality observed in patients under 'full treatment' who were not intubated. The vertical dotted line refers to summary estimate of intra-hospital mortality observed in patients under 'full treatment' who were not intubated. Red squares indicate individual study estimates of intra-hospital mortality observed in patients under 'full treatment' who were not intubated, whereas the black horizontal lines indicate the $95 \%$ confidence interval of single studies. The diamond refers to the summary estimate with $95 \%$ confidence interval 
in the modalities of proceeding toward intubation or continuing NIRS. In this regard, other factors, such as the availability of resources and the strategy of their allocation, might have adversely influenced the process of care [7, 45].

As a clinical implication, our findings, in agreement with previous suggestions [47], support the use of NIV for hypoxemic ARF due to COVID-19 also outside ICU, in the intermediate care unit setting.

The present investigation has several limitations requiring to be discussed. The enrolled studies were mainly retrospective investigations conducted during the first wave of COVID-19 pandemic from the end of February to the end of May 2020. Accordingly, it is worth to take into account the critical issues of the specific historical moment, characterized by the crisis of the hospital surge capacity response and the lack of a well-defined therapeutic approach. We could not provide insights on the modalities of NIRS application, conduction, and monitoring in the different settings explored because of the paucity of data retrieved. The leading part of the included studies was carried out in Italy. Thus, our conclusions cannot be generalized to other countries with different policies, practices, medical ethics, social attitudes, cultures, and religions [48-51]. We could not draw any conclusions about the efficacy of NIRS in curbing the overall intra-hospital mortality in the light of our data. Indeed, the present analysis was conducted on data retrieved exclusively from retrospective and prospective, nonrandomized investigations, accounting for indication bias and confounding. We included 3 pre-print investigations [32-34] in our analysis because of the relatively small number of studies enrolled at the time of search closure (end of February 21). This latter aspect along with the high between-study heterogeneity, the lack of a specific time point of intra-hospital mortality observation, and, in some cases, the poor data reporting could limit the possibility to draw definitive conclusions from our data.

\section{Conclusions}

This systematic review and meta-analysis summarized the evidence reported from the first wave of COVID-19 outbreak on the incidence of overall intra-hospital mortality in hospitalized patients undergoing NIRS outside the ICU. Despite the concerns arising from the crisis of hospital surge capacity response and the lack of a clinically effective therapy, delivering NIRS outside the ICU revealed overall as a feasible strategy to cope with the massive demand of ventilatory assistance even for those patients with care limitations. Our findings require to be confirmed in future investigations addressing the same topic over the following waves of COVID-19 outbreak.

\section{Abbreviations}

ARDS: Acute respiratory distress syndrome; ARF: Acute respiratory failure; CPAP: Continuous positive airway pressure; Cl: Confidence interval; COVID-19: Coronavirus-19 disease; DNI: Do-not-intubate; ICU: Intensive care unit; IMV: Invasive mechanical ventilation; NIRS: Noninvasive respiratory support; $\mathrm{PaO}_{2}$ / $\mathrm{FiO}_{2}$ : Arterial oxygen tension on inspired oxygen fraction ratio; SARS-CoV-2: Severe acute respiratory syndrome related to novel coronavirus.

\section{Supplementary Information}

The online version contains supplementary material available at https://doi. org/10.1186/s13054-021-03697-0.

Additional file 1. Search strategy of electronic database.

Additional file 2. Enrollment flow diagram.

Additional file 3. Characteristics of the enrolled investigations, overall clinical characteristics of the populations investigated in the enrolled studies, and list of studies excluded after reading the full text.

Additional file 4. Methodological quality of the included investigations.

\section{Acknowledgements}

We thank the collaborators:

Francesca Facondini ${ }^{1}$, MD; Maddalena Bitondo ${ }^{1}, \mathrm{MD}$; Mara Paneroni ${ }^{2}, \mathrm{MSC}$; Francesco Corradi ${ }^{3,4}$, MD, PhD; Chiara Cogliati ${ }^{5}$, MD; Matteo Fontana $^{6}$, MD; $^{2}$ Nicola Facciolongo ${ }^{6}, \mathrm{MD}$; Andrea Duca ${ }^{7}, \mathrm{MD}$; Dario Winterton ${ }^{8}, \mathrm{MD}$; Jonathan Montomoli ${ }^{1}, \mathrm{MD}$; Elisiana Carpagnano, MD ${ }^{9}$; Annalisa Benini ${ }^{8}, \mathrm{MD}$; Robert Fruscio ${ }^{8,10}$, MD; Luisa Verga $^{8}$, MD, Paolo Mazzola ${ }^{8,10}$, MD; Marco Carbone $^{8,10}$ MD, Giacomo Mulinacci ${ }^{8,10}$ MD, Alessandro Soria ${ }^{8}$ MD, Beatrice Noè ${ }^{8,10}, M D$; Eduardo Beck ${ }^{11}$, MD; Riccardo Di Sciacca ${ }^{8}$, MD; Davide Ippolito $^{8}$, MD; Giuseppe Bellelli ${ }^{8,10}, \mathrm{MD}$; Giuseppe Citerio ${ }^{8,10}, \mathrm{MD}$; Maria Grazia Valsecchi ${ }^{10}, \mathrm{MD}$; Andrea Biondi ${ }^{8,10}$, MD; Alberto Pesci ${ }^{8,10}$, MD; Paolo Bonfanti ${ }^{8,10}$, MD, Davide Gaudesi ${ }^{10}$, PhD; Laura Antolini ${ }^{10}$, PhD; Massimo Borelli ${ }^{12}$, MD; Federica De Giacomi $^{13}, \mathrm{MD}^{\prime}$; Giancarlo Bosio $^{13}$, MD; Nicola Latronico ${ }^{14,15}$, MD; Matteo Filippini ${ }^{15}$, MD; Marco Gemma $^{16}$, MD; Federico Cioffi ${ }^{17}$, MD; Claudia Giannotti $^{17}$, MD; Benvenuto Antonini ${ }^{18}, \mathrm{MD}$; Nicola Petrucci ${ }^{19}, \mathrm{MD}$; Simone Maria Zerbi ${ }^{20}, \mathrm{MD}$; Paolo Maniglia ${ }^{21}$, MD; Gian Paolo Castelli22, MD; Giovanni Marino ${ }^{23}$, MD; Matteo Subert ${ }^{24}$, MD; Danilo Radrizzani ${ }^{25}$, MD; Teresa S. Mediani ${ }^{26}$, MD; Ferdinando Luca Lorini ${ }^{27}$, MD; Filippo Maria Russo ${ }^{27}$, MD; Angela Faletti ${ }^{28}$, MD; Andrea Beindorf ${ }^{29}$, MD; Remo Daniel Covello ${ }^{30}$, MD; Stefano Greco ${ }^{31}$, MD; Marta M. Bizzarri $^{32}$, MD; Giuseppe Ristagno ${ }^{33}$, MD; Francesco Mojoli ${ }^{34}$, MD; Andrea Pradella ${ }^{35}$, MD; Paolo Severgnini ${ }^{36}$, MD; Marta Da Macallè $^{36}$, MD; Andrea Albertin $^{37}$, MD; Tommaso Tonetti ${ }^{38}$, MD; Emanuele Rezoagli ${ }^{10,39,40}$, MD, PhD; Giovanni Vitale ${ }^{39}$, MD; A ; rora Magliocca ${ }^{10,39}$, MD; Gianluca Cappelleri ${ }^{41}$, MD; Mattia Docci ${ }^{10,42}$, MD; Filippo Serra $^{10}$, MD; Emanuela Rossi ${ }^{10}$, MD; Francesco Blasi ${ }^{43,44}$, MD; $^{\prime}$ Pierachille Santus ${ }^{45}$, MD; Valer Monzani $^{46}$, MD; Antonio $^{\prime}$ Messina ${ }^{47}, M D, P h D$.

Affiliations:

${ }^{1}$ Department of Anesthesia and Intensive Care, Infermi Hospital, AUSL della Romagna, Rimini, Italy

${ }^{2}$ Respiratory Rehabilitation Unit Lumezzane, ICS Maugeri IRCCS, Brescia, Italy.

${ }^{3}$ Anesthesia and Intensive Care Unit, E.O. Ospedali Galliera, Genoa, Italy

${ }^{4}$ Department of Surgical, Medical, Molecular Pathology and Critical Care Medicine, University of Pisa, Pisa, Italy

${ }^{5}$ Department of Biomedical and Clinical Sciences Luigi Sacco, University of Milan, Ospedale Luigi Sacco, Milan, Italy

${ }^{6}$ Pneumology Unit, Arcispedale Santa Maria Nuova, Azienda USL-IRCCS di Reggio Emilia, Reggio Emilia, Italy

${ }^{7}$ Emergency Department, ASST Papa Giovanni XXIII, Bergamo, Italy

${ }^{8}$ ASST Monza, San Gerardo Hospital, Monza, Italy

${ }^{9}$ Cardiothoracic Department, Respiratory Unit, University Hospital, Bari, Italy Monza

${ }^{10}$ Department of Medicine and Surgery, University of Milan-Bicocca,

$$
{ }^{11} \text { ASST Monza, Desio Hospital, Desio, Italy }
$$


${ }^{12}$ Department of Anesthesia and Intensive Care Medicine, Treviglio-Caravaggio Hospital, ASST Bergamo Ovest, Treviglio, Italy

${ }^{13}$ Division of Pulmonary Medicine, Cremona Hospital, ASST Cremona, Cremona, Italy

${ }^{14}$ Department of Anesthesiology, Intensive Care and Emergency, Spedali Civili University Hospital, ASST Spedali Civili, Brescia, Italy

${ }^{15}$ Department of Surgical Specialties, Radiological Sciences and Public Health, University of Brescia, Brescia, Italy

${ }^{16}$ Department of Anesthesia and Intensive Care Unit, Fatebenefratelli Hospital, ASST Fatebenefratelli Sacco, Milan, Italy

${ }^{17}$ Department of Anesthesiology and Intensive Care, Luigi Sacco Hospital, ASST Fatebenefratelli Sacco, Polo Universitario, University of Milan, Milan, Italy

${ }^{18}$ Department of Anesthesiology and Intensive Care Medicine, Manerbio Hospital, ASST Garda, Brescia, Italy

${ }^{19}$ Department of Anesthesia and Intensive Care Unit, Desenzano Hospital, ASST Garda, Desenzano, Brescia, Italy

${ }^{20}$ Anesthesia and Intensive Care Unit 2, Sant'Anna Hospital, ASST Lariana, San Fermo della Battaglia, Como, Italy

${ }^{21}$ Department of Anesthesia and Intensive Care Medicine, Alessandro Manzoni Hospital, ASST Lecco, Lecco, Italy

${ }^{22}$ Department of Anesthesia and Intensive Care Medicine, Carlo Poma Hospital, ASST Mantova, Mantova, Italy

${ }^{23}$ Department of Anesthesia and Intensive Care Medicine, Vizzolo Predabissi Hospital, ASST Melegnano e della Martesana, Melegnano, Milan, Italy

${ }^{24}$ Department of Anesthesia and Intensive Care Medicine, Melzo-Gorgonzola Hospital, ASST Melegnano e della Martesana, Milano, Italy

${ }^{25}$ Department of Anesthesia and Intensive Care Medicine, Legnano Hospital, ASST Ovest milanese, Legnano, Milano, Italy

${ }^{26}$ Department of Anesthesia and Intensive Care Medicine, Vigevano Hospital, ASST Pavia, Vigevano, Pavia, Italy

${ }^{27}$ Department of Anesthesia and Intensive Care, ASST Papa Giovanni XXIII, Bergamo, Italy

${ }^{28}$ Department of Anesthesia and Intensive Care Medicine, Gardone Val Trompia Hospital, ASST Spedali Civili, Brescia, Italy

${ }^{29}$ Department of Anesthesia and Intensive Care Medicine, Montichiari Hospital, ASST Spedali Civili, Brescia, Italy

${ }^{30}$ Department of Anesthesia and Intensive Care Medicine, Busto Arsizio Hospital, ASST Valle Olona, Varese, Italy

${ }^{31}$ Department of Anesthesia and Intensive Care Medicine, Saronno Hospital, ASST Valle Olona, Varese, Italy

${ }^{32}$ Department of Anesthesia and Intensive Care Medicine, Vimercate Hospital, ASST Vimercate, Monza e Brianza, Italy

${ }^{33}$ Department of Anesthesia, Intensive Care and Emergency, Fondazione IRCCS Ca' Granda Ospedale Maggiore Policlinico, Milan, Italy

${ }^{34}$ Department of Anesthesia and Intensive Care Unit, Fondazione IRCCS Policlinico San Matteo and University of Pavia, Pavia, Italy

${ }^{35}$ Department of Anaesthesia and Intensive Care Medicine, Humanitas Clinical and Research Center - IRCCS, via Manzoni 56, 20089 Rozzano (Mi) - Italy

${ }^{36}$ Biotechnology and Life Sciences Department, Insubria University-Anesthesia and Intensive Care Circolo and Fondazione Macchi Hospital, ASST Sette Laghi, Varese (Italy)

${ }^{37}$ Department of Anesthesia and Intensive Care Medicine, San Giuseppe Hospital, Milan, Italy

${ }^{38}$ Department of Anesthesia and Intensive Care Medicine, Policlinico di Sant'Orsola, Alma Mater Studiorum University of Bologna, Bologna, Italy Italy

${ }^{39}$ Policlinico San Marco, San Donato Group Hospitals, Zingonia, Bergamo,

${ }^{40}$ Department of Anesthesia and Intensive Care Medicine, San Gerardo

Hospital, ASST Monza, Monza e Brianza, Italy

${ }^{41}$ Humanitas Gavazzeni, Bergamo (Italy)

${ }^{42}$ Policlinico San Pietro, Ponte San Pietro, Italy

${ }^{43}$ Fondazione IRCCS Ca'Granda Ospedale Maggiore Policlinico, Respiratory Unit and Cystic Fibrosis Adult Center, Milan, Italy. University of Milan,

${ }^{44}$ Department of Pathophysiology and T transplantation, Milan, Italy

${ }^{45}$ Ospedale L. Sacco, ASST Fatebenefratelli-Sacco, Division of Respiratory Diseases, Milano, Italy.

${ }^{46}$ Fondazione IRCCS Ca' Granda Ospedale Maggiore Policlinico, Department of Medicine - Acute Medical Unit, Milan, Italy

${ }^{47}$ Department of Anesthesia and Intensive Care Medicine, Humanitas Clinical and Research Center - IRCCS, Rozzano, Italy

\section{Authors' contributions}

All authors listed concur with the submitted version of the manuscript and with the listing of the authors. In particular, all authors meet the following criteria for authorship: 1. substantial contributions to the conception or design of the work; or the acquisition, analysis, or interpretation of data for the work; 2. drafting or revising the manuscript; 3 . final approval of the version submitted for publication; 4. accountability for all aspects of the work in ensuring that questions related to the accuracy or integrity of any part of the work are appropriately investigated and resolved. GC, TE helped in acquisition and analysis of data for the work. GC contributed to conception and design of the work; DA statistically analyzed the data; GC, EDR interpreted the data for the work; GC, RV, PN, ST, EDR drafted the manuscript; RC, FM, SA, AC, GB, GF, GG, $M C, A P, M V, T L, V M R, S L D D, O R, A G, A P, G N, C B$, ST shared supplemental data from their databases; GC, TE, RC, FM, SA, AC, GB, GF, GG, MC, AP, MV, TL, VMR, $S L D D, O R, A G, A P, G N, C B, S T, P N, S T, R V$, EDR revised the final version.

\section{Funding}

Not applicable.

\section{Availability of data and materials}

The datasets used and/or analyzed during the current study are available from the corresponding author on reasonable request.

\section{Declarations}

\section{Ethics approval and consent to participate}

Not applicable.

\section{Consent for publication}

Not applicable.

\section{Competing interests}

The following authors declare to have no conflicts of interest: Prof Gianmaria Cammarota, Dr. Teresa Esposito, Dr. Francesco Menzella, Prof Stefano Aliberti, Dr Michele Vitacca, Prof V. Marco Ranieri, Prof Onofrio Resta, Dr Antonio Gidaro, Dr Antonella Potalivo, Dr Giuseppe Nardi, Dr Claudia Brusasco, and Prof Rosanna Vaschetto. Dr. Roberto Cosentini reports personal fees from Fisher \& Paykel, outside the submitted work. Prof. Giuseppe Foti declares conference fees from DIMAR. Dr. Andrea Coppadoro has a patent and received consultancy fees from Flowmeter. Prof. Giacomo Grasselli declares personal fees (payment for lectures) from Getinge, Biotest, Draeger Medical, MSD, Fisher\&Paykel; travel/accommodation/congress registration support from Biotes and Getinge; unrestricted research grant from Fisher\&Paykel, MSD all outside the submitted work. Prof. Giacomo Bellani reports personal fees from Dimar and Intersurgical and is owner of a patent potentially related to this manuscript, personal fees from Draeger, Getinge, Hamilton, GE Healthcare not related to this work. Prof. Maurizio Cecconi reported personal fees from Edwards Lifesciences, Directed Systems, and Cheetah Medical outside the submitted work. Prof. Antonio Pesenti reports personal fees from Maquet, Xenios, Baxter, and Boehringer Ingelheim, outside the submitted work. Dr. Sandro Luigi Di Domenico declares relationship with Menarini group on behalf of Dynamicon education s.r.l. Dr. Tom Lawton is involved in the development of an opensource CPAP device for use in low-income countries under an EPSRC grant (no funding received). Prof. Paolo Navalesi declares to have received: grants, personal fees, and nonfinancial support from Maquet Critical Care; grants and nonfinancial support from Draeger and Intersurgical S.p.A; and personal fees from Oriopharma, Philips, Resmed, MSD, and Novartis, in each case for reasons that remain unrelated to the submitted work. Prof. Navalesi also contributed to the development of the patented 'helmet Next,'the royalties for which are paid to Intersurgical Spa. Prof. Navalesi contributed to the development of a device not discussed in the present study with patent application number: EP20170199831. Dr. Simonetta Tesoro received conference fees from MSD. Prof. Edoardo De Robertis received conference fees from MSD and Baxter.

\section{Author details}

${ }^{1}$ Department of Medicine and Surgery, University of Perugia, Piazza Università 1, 06123 Perugia, Italy. ${ }^{2}$ Department of Translational Medicine, University of Eastern Piedmont, Novara, Italy. ${ }^{3}$ Emergency Department, ASST Papa Giovanni XXIII, Bergamo, Italy. ${ }^{4}$ Pneumology Unit, Arcispedale Santa Maria Nuova, Azienda USL-IRCCS Di Reggio Emilia, Reggio Emilia, Italy. ${ }^{5}$ Respiratory 
Unit and Cystic Fibrosis Adult Center, Fondazione IRCCS Ca' Granda Ospedale Maggiore Policlinico, Milan, Italy. ${ }^{6}$ Department of Pathophysiology and Transplantation, University of Milan, Milan, Italy. ${ }^{7}$ ASST Monza, San Gerardo Hospital, Monza, Italy. ${ }^{8}$ Department of Medicine and Surgery, University of Milan-Bicocca, Monza, Italy. ${ }^{9}$ Department of Anesthesia, Intensive Care and Emergency, Fondazione IRCCS Ca'Granda Ospedale Maggiore Policlinico, Milan, Italy. ${ }^{10}$ Department of Anesthesia and Intensive Care Medicine, Humanitas Clinical and Research Center - IRCCS, Rozzano, Italy. ${ }^{11}$ Department of Biomedical Sciences, Humanitas University, Milan, Italy. ${ }^{12}$ Respiratory Rehabilitation Unit Lumezzane, ICS Maugeri IRCCS, Brescia, Italy. ${ }^{13}$ Department of Anesthesia and Critical Care, Bradford Teaching Hospitals NHS Foundation Trust, Bradford, UK. ${ }^{14}$ Anesthesia and Intensive Care Medicine, Policlinico Di Sant'Orsola, Alma Mater Studiorum University of Bologna, Bologna, Italy. ${ }^{15}$ Department of Emergency Medicine, ASST Grande Ospedale Metropolitano Niguarda, Milan, Italy. ${ }^{16}$ Cardiothoracic Department, Respiratory Unit, University Hospital, Bari, Italy. ${ }^{17}$ Department of Biomedical and Clinical Sciences Luigi Sacco, University of Milan, Ospedale Luigi Sacco, Milan, Italy. ${ }^{18}$ Department of Anesthesia and Intensive Care, Infermi Hospital, AUSL Della Romagna, Rimini, Italy. ${ }^{19}$ Anesthesia and Intensive Care Unit, E.O. Ospedali Galliera, Genoa, Italy. ${ }^{20}$ Department of Medicine-DIMED, Università Di Padova, Padua, Italy.

\section{Received: 29 March 2021 Accepted: 21 July 2021}

\section{Published online: 30 July 2021}

\section{References}

1. Zhou P, Yang X Lou, Wang XG, Hu B, Zhang L, Zhang W, et al. A pneumonia outbreak associated with a new coronavirus of probable bat origin. Nature; 2020.

2. Zhou F, Yu T, Du R, Fan G, Liu Y, Liu Z, et al. Clinical course and risk factors for mortality of adult inpatients with COVID-19 in Wuhan, China: a retrospective cohort study. Lancet; 2020.

3. Wang D, Hu B, Hu C, Zhu F, Liu X, Zhang J, et al. Clinical characteristics of 138 hospitalized patients with 2019 novel coronavirus-infected pneumonia in Wuhan, China. JAMA J Am Med Assoc. 2020;323:1061-9.

4. Goyal P, Choi JJ, Pinheiro LC, Schenck EJ, Chen R, Jabri A, et al. Clinical characteristics of Covid-19 in New York City. N Engl J Med. 2020;382:2372-4.

5. Richardson S, Hirsch JS, Narasimhan M, Crawford JM, McGinn T, Davidson $\mathrm{KW}$, et al. Presenting characteristics, comorbidities, and outcomes among 5700 patients hospitalized with COVID-19 in the New York City Area. JAMA - J Am Med Assoc. 2020.

6. Cammarota G, Ragazzoni L, Capuzzi F, Puiulvirenti S, Santangelo E, Verdina F, et al. Critical care surge capacity to respond to the COVID-19 pandemic in Italy : a rapid and affordable solution in the Novara Hospital. Prehosp Disaster Med. 2020;35:431-3.

7. Vitacca M, Nava S, Santus P, Harari S. Early consensus management for non-ICU ARF SARS-CoV-2 emergency in Italy: from ward to trenches. Eur Respir J. 2020;55:2000632.

8. Grasselli G, Zangrillo A, Zanella A, Antonelli M, Cabrini L, Castelli A, et al. Baseline characteristics and outcomes of 1591 patients infected with SARS-CoV-2 admitted to ICUs of the Lombardy region, Italy. JAMA - J Am Med Assoc. 2020.

9. Yang $X, Y u Y, X u J$, Shu H, Xia J, Liu H, et al. Clinical course and outcomes of critically ill patients with SARS-CoV-2 pneumonia in Wuhan, China: a single-centered, retrospective, observational study. Lancet Respir Med Elsevier Ltd. 2020;8:475-81.

10. Franco C, Facciolongo N, Tonelli R, Dongilli R, Vianello A, Pisani L, et al. Feasibility and clinical impact of out-of-ICU noninvasive respiratory support in patients with COVID-19-related pneumonia. Eur Respir J. 2020;56:2002130.

11. Vaschetto R, Barone-Adesi F, Racca F, Pissaia C, Maestrone C, Colombo D, et al. Outcomes of COVID-19 patients treated with continuous positive airway pressure outside the intensive care unit. ERJ Open Res. 2021;7:00541-2020.

12. Frat JP, Thille AW, Mercat A, Girault C, Ragot S, Perbet S, et al. High-flow oxygen through nasal cannula in acute hypoxemic respiratory failure. $\mathrm{N}$ Engl J Med. 2015;372:2185-96.
13. Brochard L, Slutsky AS, Pesenti A. Critical care perspective mechanical ventilation to minimize progression of lung injury in acute respiratory failure. Am J Respir Crit Care Med. 2017;195:438-42.

14. Brochard L, Lefebvre JC, Cordioli RL, Akoumianaki E, Richard JCM. Noninvasive ventilation for patients with hypoxemic acute respiratory failure. Semin Respir Crit Care Med. 2014;35:492-500.

15. Rochwerg B, Brochard L, Elliott MW, Hess D, Hill NS, Nava S, et al. Official ERS/ATS clinical practice guidelines: noninvasive ventilation for acute respiratory failure. Eur Respir J. 2017;50:1-20.

16. Moher D, Liberati A, Tetzlaff J, Altman DG, Group TP. Preferred reporting items for systematic reviews and meta-analyses : the PRISMA statement. PLOS Med. 2009;6.

17. Potere N, Valeriani E, Candeloro M, Tana M, Porreca E, Abbate A, et al. Acute complications and mortality in hospitalized patients with coronavirus disease 2019: a systematic review and meta-analysis. Crit Care Critical Care. 2020;24:1-12.

18. Slim K, Nini E, Forestier D, Kwiatkowski F, Panis Y, Chipponi J. Methodological index for non-randomized studies (Minors): Development and validation of a new instrument. ANZ J Surg. 2003;73:712-6.

19. Higgins JP, Thompson SG, Deeks JJ, Altman DG. Measuring inconsistency in meta-analyses. J Intell Inf Syst. 2006;27:159-84.

20. Menzella F, Fontana M, Salvarani C, Massari M, Ruggiero P, Scelfo C, et al. Efficacy of tocilizumab in patients with COVID-19 ARDS undergoing noninvasive ventilation. Crit Care. 2020;24:589.

21. Ramirez GA, Bozzolo EP, Castelli E, Marinosci A, Angelillo P, Damanti S, et al. Continuous positive airway pressure and pronation outside the intensive care unit in COVID 19 ARDS. Minerva Med. Italy; 2020.

22. Avdeev SN, Yaroshetskiy Al, Tsareva NA, Merzhoeva ZM, Trushenko NV, Nekludova GV, et al. Noninvasive ventilation for acute hypoxemic respiratory failure in patients with COVID-19. Am J Emerg Med. 2021;39:154-7.

23. Brusasco C, Corradi F, Di Domenico A, Raggi F, Timossi G, Santori G, et al. Continuous positive airway pressure in Covid-19 patients with moderateto-severe respiratory failure. Eur Respir J. 2020;57:2002524.

24. Duca A, Memaj I, Zanardi F, Preti C, Alesi A, Della Bella L, et al. Severity of respiratory failure and outcome of patients needing a ventilatory support in the Emergency Department during Italian novel coronavirus SARS-CoV2 outbreak: preliminary data on the role of Helmet CPAP and non-invasive positive pressure Ventilation. EClinicalMedicine Elsevier Ltd. 2020;24:1-7.

25. Aliberti S, Radovanovic D, Billi F, Sotgiu G, Costanzo M, Pilocane T, et al. Helmet CPAP treatment in patients with COVID-19 pneumonia: a multicentre cohort study. Eur Respir J. 2020;56:2001935.

26. Di Domenico SL, Coen D, Bergamaschi M, Albertini V, Ghezzi L, Cazzaniga MM, et al. Clinical characteristics and respiratory support of 310 COVID-19 patients, diagnosed at the emergency room: a single-center retrospective study. Int Emerg Med. 2020;16:1051-60.

27. Faraone A, Beltrame C, Crociani A, Carrai P, Lovicu E, Filetti S, et al. Effectiveness and safety of noninvasive positive pressure ventilation in the treatment of COVID-19-associated acute hypoxemic respiratory failure: a single center, non-ICU setting experience. Int Emerg Med. 2020;1-8.

28. Potalivo A, Montomoli J, Facondini F, Sanson G, Lazzari Agli LA, Perin T, et al. Sixty-day mortality among 520 Italian hospitalized COVID-19 patients according to the adopted ventilatory strategy in the context of an integrated multidisciplinary clinical organization: a population-based cohort study. Clin Epidemiol. 2020;12:1421-31.

29. Di Lecce V, Carpagnano GE, Pierucci P, Quaranta VN, Barratta F, Zito A, et al. Baseline characteristics and outcomes of COVID-19 patients admitted to a respiratory intensive care unit (RICU) in Southern Italy. Multidiscip Respir Med. 2020;15:704.

30. Bellani G, Grasselli G, Cecconi M, Antolini L, Borelli M, Giacomi F De, et al. Noninvasive ventilatory support of COVID-19 patients outside the intensive care units (WARd-COVID). Ann Am Thorac Soc. 2021.

31. Coppadoro A, Fruscio R, Verga L, Soria A, Noe B, Sciacca R Di, et al. Helmet CPAP to Treat Hypoxic Pneumonia Outside the ICU : An Observational Study During the COVID- 19 Outbreak. Crit Care. 2020;25.

32. Gidaro A, Samartin F, Brambilla AM, Cogliati C, Ingrassia S, Banfi F, et al. Occurrence of pneumothorax and pneumomediastinum in Covid-19 patients during non-invasive ventilation with continuous positive airway pressure. medRxiv. 2020; 
33. Noeman-Ahmed Y, Gokaraju S, Powrie DJ, Amran DA, El Sayed I, Roshdy A. Predictors of CPAP outcome in hospitalised COVID-19 patients. medRxiv. 2020.

34. Lawton T, Corp AP, Javid R, MacNally L, McCooe M, Newton E. Reduced ICU demand with early CPAP and proning in COVID-19 at Bradford: a single centre cohort. medRxiv. 2020.

35. Huang C, Wang Y, Li X, Ren L, Zhao J, Hu Y, et al. Clinical features of patients infected with 2019 novel coronavirus in Wuhan. China Lancet. 2020;395:497-506.

36. Guan W, Ni Z, Hu Y, Liang W, Ou C, He J, et al. Clinical characteristics of coronavirus disease 2019 in China. N Engl J Med. 2020;382:1708-20.

37. Bellani G, Laffey JG, Pham T, Madotto F, Fan E, Brochard L, et al. Noninvasive ventilation of patients with acute respiratory distress syndrome: insights from the LUNG SAFE study. Am J Respir Crit Care Med. 2017;195:67-77.

38. Grieco DL, Menga LS, Cesarano M, Rosà T, Spadaro S, Bitondo MM, et al. Effect of helmet noninvasive ventilation vs high-flow nasal oxygen on days free of respiratory support in patients with COVID-19 and moderate to severe hypoxemic respiratory failure: the HENIVOT randomized clinical trial. JAMA - J Am Med Assoc. 2021;325:1731-43.

39. Cheung TMT, Yam LYC, So LKY, Lau ACW, Kong BMH, Yung RWH. Effectiveness of noninvasive positive pressure ventilation in the treatment of acute respiratory failure in severe acute respiratory syndrome. Chest. 2004; 126:845-50.

40. Esquinas AM, Egbert Pravinkumar S, Scala R, Gay P, Soroksky A, Girault C, et al. Noninvasive mechanical ventilation in high-risk pulmonary infections: a clinical review. Eur Respir Rev. 2014;23:427-38.

41. Alraddadi BM, Qushmaq I, Al-Hameed FM, Mandourah Y, Almekhlafi GA, Jose J, et al. Noninvasive ventilation in critically ill patients with the middle east respiratory syndrome. Influenza Other Respi Viruses. 2019;13:382-90.

42. Brochard L, Slutsky A, Pesenti A. Mechanical ventilation to minimize progression of lung injury in acute respiratory failure. Am J Respir Crit Care Med. 2017;195:438-42.
43. Wilson ME, Mittal A, Karki B, Dobler CC, Wahab A, Curtis JR, et al. Do-notintubate orders in patients with acute respiratory failure: a systematic review and meta-analysis. Intensive Care Med. 2020;46:36-45.

44. Wilson ME, Majzoub AM, Dobler CC, Curtis JR, Nayfeh T, Thorsteinsdottir B, et al. Noninvasive ventilation in patients with do-not-intubate and comfort-measures-only orders: a systematic review and meta-analysis. Crit Care Med. 2018;46:1209-16.

45. Alhazzani W, Moller MH, Arabi YM, Loeb M, Gong MN, Fan E, et al. Surviving sepsis campaign: guidelines on the management of critically ill adults with Coronavirus Disease 2019 (COVID-19). Intensive Care Med. 2020;46:854-87.

46. Grasselli G, Greco M, Zanella A, Albano G, Antonelli M, Bellani G, et al. Risk factors associated with mortality among patients with COVID-19 in intensive care units in Lombardy, Italy. JAMA Intern Med. 2020;1-11.

47. Chalmers JD, Crichton ML, Goeminne PC, Cao B, Humbert M, Shteinberg $M$, et al. Management of hospitalised adults with coronavirus disease-19 (COVID-19): a European Respiratory Society living guideline. Eur Respir J. 2021;57:2100048

48. Quill CM, Ratcliffe SJ, Harhay MO, Halpern SD. Variation in decisions to forgo life-sustaining therapies in US ICUs. Chest. 2014;146:573-82.

49. Long AC, Brumback LC, Curtis JR, Avidan A, Baras M, De RE, et al. Agreement with consensus statements on end-of-life care: a description of variability at the level of the provider, hospital, and country. Crit Care Med. 2020;47:1396-401.

50. Santonocito C, Ristagno G, Gullo A, Weil MH. Do-not-resuscitate order: a view throughout the world. J Crit Care. 2013;28:14-21.

51. Johnson Shen M, Prigerson HG, Paulk E, Trevino K, Penedo FJ, Tergas Al, et al. Impact of end-of-life discussions on the reduction of Latino/nonLatino disparities in DNR order completion. Cancer. 2016;122:1749-56.

\section{Publisher's Note}

Springer Nature remains neutral with regard to jurisdictional claims in published maps and institutional affiliations.
Ready to submit your research? Choose BMC and benefit from:

- fast, convenient online submission

- thorough peer review by experienced researchers in your field

- rapid publication on acceptance

- support for research data, including large and complex data types

- gold Open Access which fosters wider collaboration and increased citations

- maximum visibility for your research: over 100M website views per year

At BMC, research is always in progress.

Learn more biomedcentral.com/submissions 